\title{
Chemometric analysis of the secondary metabolite profile of Yarrow (Achillea collina Becker ex Rchb.) affected by phloem feeding Myzus persicae Sulzer aphids
}

\begin{abstract}
Yarrow (Achillea collina Becker ex Rchb.) has a high content of secondary metabolites including phenolic acids. Among them, hydroxycinnamic acid such as chlorogenic acid and its derivatives were found to be the most abundant ones. The phloem feeding Myzus persicae Sulzer was hypothesized to affect the contents of secondary metabolites and change the metabolite profile. A high-performance liquid chromatography technique (HPLC) was used to evaluate whether there is a difference in the phenolic profile between aphid infested and non-infested yarrow leaves. $M$. persicae colonies composed of between 20 and 30 individuals were allowed to feed for 10 and 20 days. Preprocessing was carried out to standardize the procedures in order to obtain optimal separation of analytes, good chromatographic peak shape and robustness of the results. The methanol extracts of leaves were analyzed by means of HPLC, and the time series of peak areas obtained from each extract were evaluated through chemometric analyses. Results of the phenolic fingerprints showed a specific chromatographic profile with 58 peaks. An autoregression analysis demonstrated the absence of correlation. The discriminant analysis carried out with the data satisfying the assumption of the absence of collinearity showed a significant effect of phloem feeding on soluble phenolic compounds and identified two peaks that separate aphid infested from non-infested plants. The hydroxycinnamic acids widely found in A. collina leaves were not affected by $M$. persicae feeding. The results are the basis for the current studies aiming at the identification of chemical compounds that correspond to the peaks.
\end{abstract}

Riassunto - Analisi chemometrica del profilo dei metaboliti secondari di Achillea collina Becker ex Rchb. infestata da afidi appartenenti alla specie Myzus persicae Sulzer

Achillea collina Becker ex Rchb. è una pianta medicinale caratterizzata da un alto contenuto in metaboliti secondari, in particolare in acidi fenolici. Tra questi, gli acidi idrossicinnamici quali il clorogenico e suoi derivati sono risultati essere i più abbondanti. Variazioni qualitative e quantitative di tali metaboliti sono state osservate in seguito ad attacchi entomatici. Si ipotizza che Myzus persicae Sulzer, afide che si nutre di sostanze floematiche, possa modificare il contenuto degli acidi fenolici della pianta. E' stata impiegata la tecnica di cromatografia liquida ad alta 
prestazione (HPLC) per valutare se vi sono differenze nel profilo degli acidi fenolici in estratti metanolici di foglie di A. collina non infestate e infestate con M.persicae. Ad una colonia di afidi costituita da 20-30 individui è stato permesso di nutrirsi sulle piante per 10 o 20 giorni. Una procedura di messa a punto del metodo analitico ("preprocessing") è stata effettuata per standardizzare l'analisi, così da ottenere una ottimale separazione e risoluzione degli analiti, garantendo la robustezza dei risultati. Le sequenze delle aree dei picchi ottenute da ciascun estratto sono state valutate con procedure chemometriche. Il profilo dell'estratto metanolico caratteristico è risultato avere 58 picchi cromatografici. Analisi di auto regressione dimostrarono l'assenza di correlazione tra i picchi. L'analisi discriminante effettuata sui dati che soddisfano l'ipotesi di assenza di collinearità ha mostrato un effetto significativo della presenza degli afidi sui composti fenolici presenti nell'estratto metanolico. Due picchi, in particolare, sono risultati essere discriminanti tra piante non infestate e piante infestate. Gli acidi idrossicinnamici precedentemente identificati in foglie di A. collina non sono stati influenzati dall'attacco di M. persicae. I risultati fin qui ottenuti hanno posto la base per gli attuali studi, che hanno lo scopo di identificare la struttura chimica delle sostanze corrispondenti ai due picchi discriminanti.

Key words: Achillea collina Becker ex Rchb, Myzus persicae Sulzer, secondary metabolites, hydroxycinnamic acids, chemometrics, autoregression, discriminant analysis.

\section{INTRODUCTION}

Secondary metabolites, i.e. organic compounds that are not directly involved in the normal growth, development, or reproduction of organisms (Fraenkel, 1959; Dixon, 2001; Wink, 2003; Benderoth et al., 2006), are widely distributed in plants (Ramachandra Rao et al., 2002). In response to biotic and abiotic stresses, plants may increase the production of these substances and select different pathways for their synthesis (Grace \& Logan, 2000; Hadacek, 2002; Wink, 2003). A complex genetic system contributes to the shaping of single and multiple signaling pathways and to the rapid accumulation of secondary metabolites which play an important role during disease infection or herbivore attack (Hartmann, 2004; Edreva et al., 2008, Walling, 2000). The current literature emphasizes the role of the secondary metabolites in plant herbivore interaction, although the plant is known to react with other biochemicals and biophysical elements to herbivore attack (Schowalter, 2006; Wittstock et al., 2004). The accumulation of phenolic compounds, emission of a higher number of volatiles, generation of hydrogen peroxide, localized cell death and synthesis of hydrolytic enzymes, often accompany the symptoms of stenophagous herbivore and pathogen attack (Moran et al., 2002). Because of their economic importance, phloem feeding aphids have received particular attention in investigations on secondary metabolites (Pichersky et al., 2000; Moran et al., 2002). Aphids have the potential to rapidly increase their population densities and phloem sap consumption (Kuśnierczyk et al., 2008).

Yarrow, Achillea collina Becker ex Rchb. belonging to the Asteraceae family, has a high content of secondary metabolites of interest in human medicine. Namely, aqueous 
and alcoholic extracts have digestive, antiphlogistic, spasmolytic, stomachic, carminative, estrogenic properties (Benedek et al., 2007). Previous investigations pointed out that the SPAK cultivar is rich in hydroxycinnamic acids such as chlorogenic acid, 3,5-di- $O$-caffeoylquinic acid and 4,5-di- $O$-caffeoylquinic acid (Giorgi et al., 2009). These compounds are produced in the shikimate pathway and implicated in structural support, pigmentation and mechanisms that increase the plant capacity to react to stress by scavenging reactive oxygen species (Bennett \& Wallsgrove, 1994; Dixon \& Paiva, 1995; Wink, 2003). Recent work reported that oils distilled from several species of Artemisia and Achillea showed some promise as aphid repellents (Halbert et al., 2008). Yarrow is a host plant for several aphids including the green peach aphid Myzus persicae Sulzer, which is a phloem feeding insect infesting plants belonging to more than 30 plant families (van Enden et al., 1969, Hill, 1983). M. persicae is widely used in ecological studies due to the versatility in colony maintaining (Moran et al., 2002).

The purpose of this work is to evaluate the response of yarrow to phloem feeding by $M$. persicae on the basis of phenolics. Specifically, the study evaluates whether there is a difference in phenolic metabolites between aphid infested and non-infested plants and aims to identify the compounds separating infested from non-infested plants. This is done by relying on the High Performance Liquid Chromatography (HPLC) methodology and a chemometric approach to the analysis of the chromatograms.

\section{Reagents}

\section{MATERIALS AND METHODS}

Chlorogenic acid (5-O-caffeoylquinic acid, purity $>95 \%$ ) and all the other chemicals and reagents of analytical and HPLC grade were purchased from Sigma-Aldrich (Milan, Italy). 3,5-di- $O$-caffeoylquinic acid was isolated and purified from yarrow, and its structure was determined on the basis of NMR and ESI-MS data. The purities exceeded 95\% as determined by HPLC analysis (Giorgi et al., 2009).

\section{Plant material and aphid infestation}

Seeds of the A. collina cultivar "SPAK" (Valplantons Bio company; Saillons, Switzerland) were sown in a mixture of standard garden substrate and perlite. Ten days after emergence, they were transplanted in plastic pots containing the same soil and placed in a greenhouse under controlled conditions. M. persicae stock cultures were maintained on Pisum sativum L. planted in pots filled with perlite and kept in a temperature-controlled glasshouse set at $21^{\circ} \mathrm{C}$, under natural light.

The experiments were carried out at a $16 \mathrm{~h}$ photophase with $21^{\circ} \mathrm{C}$ and a $8 \mathrm{~h}$ scotophase with $18{ }^{\circ} \mathrm{C}$, a constant relative humidity of $70 \%$, and daily water supply. Thirty or 50 days after germination, we infested single plants with a colony of about 20-30 individuals. After 10 or 20 days, the aphids were removed with a thin brush, and the leaves of control and infested plants were ground in liquid nitrogen and stored at $-80^{\circ} \mathrm{C}$ until the extraction of the soluble phenolic compounds. 


\section{Soluble phenolic extraction}

The amount of $0.1 \mathrm{~g}$ powdered freezed material of the aerial plant part was processed as follows. The material was mixed with $1 \mathrm{ml}$ of methyl alcohol $(\mathrm{MeOH})$ and macerated under sonication (water bath, room temperature, $30 \mathrm{~min}$ ). The supernatant was collected after centrifugation. The remaining pellet was re-dissolved in $\mathrm{MeOH}$, and the extraction was repeated. To verify a complete extraction of alcohol soluble phenolics, a spectrophotometric assay by means the Folin-Ciocalteu reagent was applied to each supernatant. The extraction process was repeated as long as phenolic molecules were detected, corresponding to the minimum value of absorbance. All the supernatants of each extract were combined, concentrated at $0.5 \mathrm{ml}$ under vacuum, filtered $(0.45 \mu \mathrm{m} \mathrm{MIL-}$ LEX® $\mathrm{HV}$, Millipore, Milan, Italy) and stored at $-20^{\circ} \mathrm{C}$. Before injection, the methanol extracts of each sample were diluted with water (HPLC grade), methanol:water (25:75).

\section{Preprocessing: HPLC analysis of phenolic compounds}

The extracts were analyzed by using the high performance liquid chromatography (HPLC). Such a technique is commonly applied in the analysis of any class of molecules, including various phenolic compounds. The conditions able to generate meaningful data depend on instrumentation attributes and the method employed in HPLC analysis. The HPLC instrument consisted of a Waters 515 pump connected to a Waters 2487 Dual $\lambda$ Absorbance UV Detector set at $290 \mathrm{~nm}$ (Waters, MI, Italy). Separations were achieved on a reversed phase column C-18 Hypersil ODS (Supelco, particle size $5 \mu \mathrm{m}, 250 \mathrm{~mm}$ $\mathrm{x} 4.6 \mathrm{~mm}$ ) with a C-18 precolumn. The column temperature was maintained at $30^{\circ} \mathrm{C}$. The signal-processing programs were obtained from the computer controlled system using upgraded Millenium32 software (Waters, MI, Italy). The results are summarized in a chromatogram, i.e. a sequence of ideally symmetrical peaks which are the detector signals plotted versus the time of separation. The preprocessing seeks standardized conditions for the optimal separation of analytes and good chromatographic peak shape. The optimal separation is the one that, by visual examination, separates best the chromatographic peaks distinguishing between the beginning of a peak and the end of the preceding peak. Such separation was achieved using as mobile phase a solution of $0.05 \%$ formic acid in water (solvent A) and methanol (solvent B) at a constant flow rate of $1 \mathrm{ml} / \mathrm{min}$. Initially a concentration of $25 \% \mathrm{~B}$ was maintained for 3 minutes. Solvent B was then increased to $70 \%$ at $24 \mathrm{~min}, 85 \%$ at $30 \mathrm{~min}, 100 \%$ at $31 \mathrm{~min}$ and finally, isocratic elution with $100 \% \mathrm{~B}$ until $36 \mathrm{~min}$, linear change to $25 \% \mathrm{~B}$, holding for $10 \mathrm{~min}$ to re-equilibrate the column to initial conditions. The injection volume was $20 \mu 1$. The hydroxycinnamic acids, previously identified in A. collina, such as chlorogenic acid and 3,5-di- $O$-caffeoylquinic acid were injected as external standard solutions.

\section{Preprocessing: validation of HPLC method}

According to ICH recommendations ( $\mathrm{ICH}, 2005)$, the robustness of the method is assessed by validating parameters such as limits of detection and quantification as well as linearity of the analytical procedure. The minimum level at which phenolic components 
of A. collina could be reliably detected was estimated through the signal-to-noise ratio $(\mathrm{S} / \mathrm{N})$ as the limits of detection and quantification calculating the amounts displaying respectively, three (LOD; $\mathrm{S} / \mathrm{N}=3$ ) and ten (LOQ; $\mathrm{S} / \mathrm{N}=10)$ times higher, then the baseline noise. The evaluation of the linearity of the calibration response is based on regression and correlation analysis. Specifically, the responses were obtained by plotting the signal, i.e. the areas of the chromatographic peaks against the different concentration of the analytes in the sample (De Backer et al., 2009). In this paper, we exclusively report the final result of the evaluation. The validation parameters were qualified by employing six additional calibration levels of chlorogenic acid, and 3,5-di- $O$-caffeoylquinic acid prepared in $25 \%$ aqueous methanol ranging from 100 to $0.05 \mu \mathrm{g} / \mathrm{ml}$ were injected in triplicate into the chromatographic system on three different days.

\section{Processing}

Treatment 1 was carried out with 30 and 50 days old plants. Plants were individually planted in pots of 0.31 covered by polyethylene cages. The number of replicates was 20. For treatment 2 , the same experimental set-up was used but the plants were infested with $M$. persicae colonies comprising between 20 and 30 individuals that were allowed to feed for 20 days. The number of replicates was 21 .

\section{Statistical analysis}

The analysis of yarrow's HPLC profiles aims at the identification of the chromatographic peaks separating treatment 1 from treatment 2 . The statistical analyses were performed using the Statistical Product and Service Solutions (SPSS) program (Version 18.0; SPSS Inc., Chicago, IL). To illustrate the sequence of the peaks, a chromatogram is presented in Figure 1. To stabilize the variance, the values $x$ of the peaks area were transformed according to $x=\log (\mathrm{x}+1)$. The sequence of peaks in each chromatographic profile provides a time series that is analysed through autocorrelation functions. The Autoregressive Integrated Moving Average Model (ARIMA) is a widely known model for detecting the presence of serial correlation providing a detailed description of the stochastic process. By means of the Ljung-Box, we tested the overall randomness to verify the absence of autocorrelation (Garey et al., 2008; Zhao et al., 2008).

To identify peaks able to separate treatments 1 and 2, a discriminant analysis was carried out. First, a multiple regression analysis was conducted to assess the collinearity and exclude the peaks that did not satisfied the criteria of both the tolerance (tolerance $>0.200)$ and the Variance Inflaction $(\mathrm{VIF}<5)$ which were specified for the SPSS software by Barbaranelli (2009). For this purpose, we employed a stepwise elimination of the peaks. Second, the effect of the remaining peaks in the two treatments was evaluated according to Wilks' lambda statistics (Barbaranelli, 2009). The smaller the value of Wilks' lambda the greater is the contribution to the discriminant function. The assumption of homeoscadisticity was not tested because the number of replicates in each treatment was similar. In this case, the discriminant analysis is robust to the violation of the assumption of homeoscadisticity (Barbaranelli, 2009). 


\section{RESULTS}

\section{Preprocessing: HPLC analysis of phenolic compounds}

The developed HPLC method was able to separate well the phenolic compounds characterizing A. collina alcoholic extracts. A separation time of 36 minutes was sufficient to obtain a satisfactory resolution of the substances, and each peak had satisfactory symmetrical shape. The retention times of standard solutions were $9.25 \pm 0.16 \mathrm{~min}$ and $17.05 \pm 0.18 \mathrm{~min}$ for chlorogenic acid and 3,5-di- $O$-caffeoylquinic acid, respectively. At these conditions, the HPLC system performs within an acceptable range of precision and linearity.

\section{Preprocessing: validation of HPLC method}

Limits of detection (LOD; $\mathrm{S} / \mathrm{N}=3$ ) and quantification (LOQ; $\mathrm{S} / \mathrm{N}=10$ ) were 0.7 and $5.0 \mu \mathrm{g} / \mathrm{ml}$ for chlorogenic acid and 1.5 and $25 \mu \mathrm{g} / \mathrm{ml}$ for 3,5-di- $O$-caffeoylquinic acid, respectively. Setting the LOD to $0.7 \mu \mathrm{g} / \mathrm{ml}$ for chlorogenic acid, we obtained the corresponding values $x$ of the peak equal to 1800 according to the machine specifications. All peaks with area value under 2000 were considered as impurity or noise and disregarded in

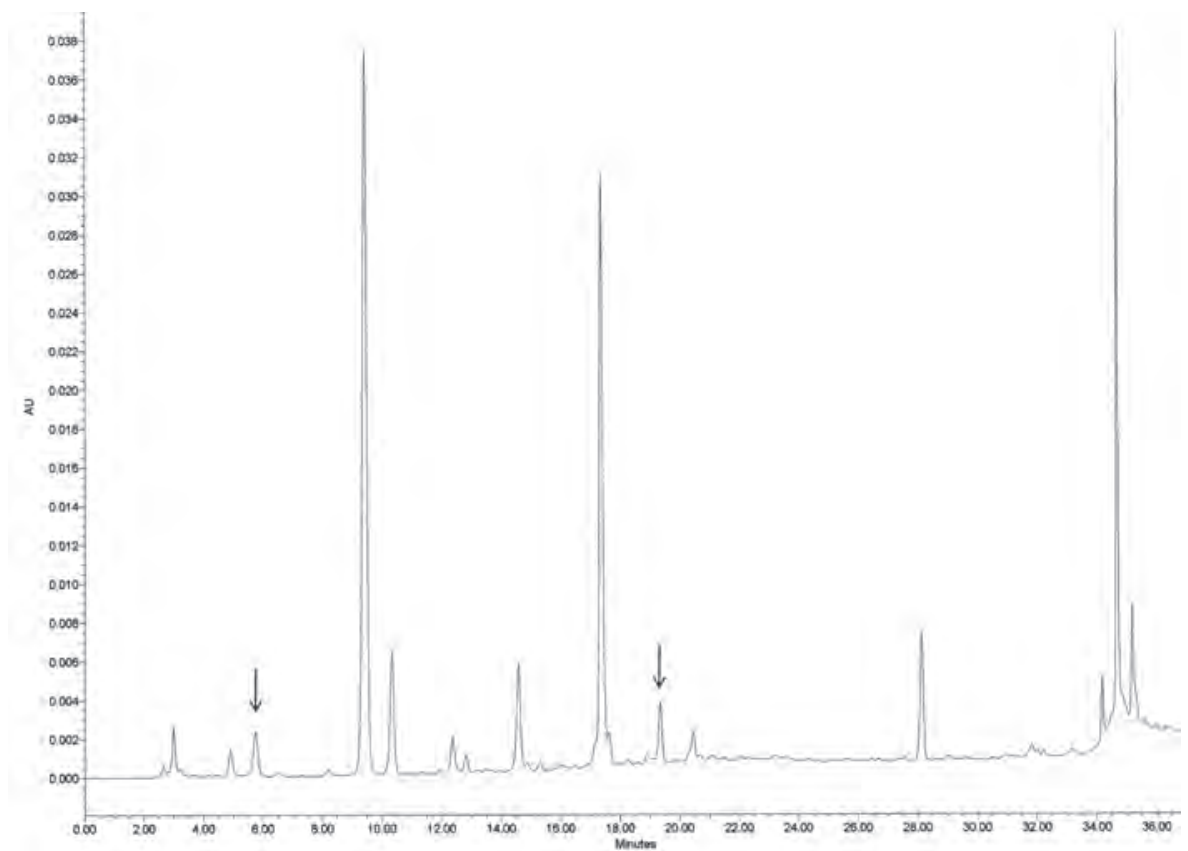

Fig. 1 - The response of Achillea collina ex Rchb. to Myzus persicae Sulzer infestation: example of chromatogram obtained from aphid infested yarrow leaves (Arrows indicate the discriminatory peaks 6 and 29, the peak obtained after 9 minutes corresponds to chlorogenic acid, the peak obtained after 17 minutes corresponds to 3,5-di- $O$-caffeoylquinic acid). 
further analyses. The response appeared to be linear over a wide range of concentrations (100 to $0.05 \mu \mathrm{g} / \mathrm{ml}$ ) for each analyte. This is supported by the responses (y) in relation to the concentrations $(\mathrm{x})$, where $\mathrm{y}=4980 \mathrm{x}+3.66$ with $r^{2}=0.999$ (chlorogenic acid) and $y=4760 \mathrm{x}+2.23$ with $r^{2}=0.999$ (3,5-di- $O$-caffeoylquinic acid).

\section{Statistical analysis of processing data}

The analysis of A. collina extracts obtained from experiments A and B provided a matrix with 20 cases for the treatment 1 (not infested) and 21 cases for the treatment 2 (infested). In each case, the chromatographic profiles showed a succession of 58 chromatographic peaks. Figure 1 shows the sequence of well separated peaks in an example of a chromatogram obtained for infested plants and illustrates the patterns that are analyze as follows.

The Autoregressive Integrated Moving Average Model (ARIMA) applied to the different samples produced only occasionally significant autocorrelations with no consistent patterns. Therefore, we disregarded the autocorrelation in further analysis.

Tab. 1 lists the 20 peaks, out of 58, that meet the tolerance criteria of collinearity in the stepwise regression analysis.

Tab. 1 - The response of Achillea collina ex Rchb. to Myzus persicae Sulzer infestation: tolerance values of the predictor variables, reported as peak number with retention time (Rt).

\begin{tabular}{|c|c|c|}
\hline Peak number & Rt (minutes) & Tolerance \\
\hline 3 & 3.25 & 0.450 \\
\hline 6 & 5.86 & 0.330 \\
\hline 13 & 9.25 & 0.266 \\
\hline 15 & 10.29 & 0.288 \\
\hline 16 & 10.42 & 0.449 \\
\hline 18 & 11.60 & 0.386 \\
\hline 19 & 12.05 & 0.419 \\
\hline 20 & 12.22 & 0.292 \\
\hline 21 & 12.62 & 0.326 \\
\hline 23 & 13.36 & 0.496 \\
\hline 29 & 19.34 & 0.437 \\
\hline 33 & 20.13 & 0.282 \\
\hline 44 & 25.89 & 0.316 \\
\hline 48 & 27.93 & 0.417 \\
\hline 50 & 28.42 & 0.489 \\
\hline 51 & 29.00 & 0.342 \\
\hline 52 & 29.42 & 0.362 \\
\hline 53 & 30.19 & 0.455 \\
\hline 54 & 31.04 & 0.370 \\
\hline 55 & 31.21 & 0.423 \\
\hline
\end{tabular}


The canonical discriminant coefficients are 0.831 for peak 6 and 0.688 for peak 29. The Wilks' Lambda value equal to 0.01 indicates a good discrimination capability (Barbaranelli, 2009). Accordingly, peak 6 and peak 29 with retention times of 5.86 and 19.34 minutes have a significant discriminatory effect. These two peaks have been marked in Figure 1.

Tab. 2 reports the predictive capability of the discriminant model. Accordingly, $73.2 \%$ was the overall hit ratio, representing the percentage of original treatments (not infested and infested). $76.2 \%$ was the correctly classified control cases while the $70.0 \%$ was the correctly classified infested cases.

Tab. 2 - The response of Achillea collina ex Rchb. to Myzus persicae Sulzer infestation: classification of the peaks obtained in the chromatograms ${ }^{\text {a. }}$

\begin{tabular}{|c|c|c|c|c|c|}
\hline \multicolumn{3}{|c|}{ Treatment } & \multicolumn{2}{|c|}{ Predicted Group Membership } & \multirow{2}{*}{ Total } \\
\cline { 4 - 5 } & & $\mathbf{1 . 0 0}$ & $\mathbf{2 . 0 0}$ & \\
\hline \multirow{3}{*}{ Original } & \multirow{3}{*}{ Count } & 1.00 & 16 & 5 & 21 \\
\cline { 4 - 6 } & & 2.00 & 6 & 14 & 20 \\
\cline { 4 - 6 } & \multirow{2}{*}{$\%$} & 1.00 & 76.2 & 23.8 & 100.0 \\
\cline { 4 - 6 } & & 2.00 & 30.0 & 70.0 & 100.0 \\
\hline
\end{tabular}

a. $73.2 \%$ of original grouped cases correctly classified.

\section{DISCUSSION}

Secondary metabolites play a major role in the adaptation of plants to their environment (Ehrlich et al., 1964; Wink, 2003; Benderoth et al., 2006). Recently, Futuyma \& Agrawal (2009) described the role of secondary metabolites in evolution theories, biodiversity and plant defense. This paper is restricted to the response of the plant in terms of phenolics and disregards other biochemicals and biophysical elements (Schowalter, 2006). Moreover, the treatment combines infestations obtained with colonies of different size feeding on the plant over 10 or 20 days time interval and compares the results with a control. More detailed information on colony sizes and the definition of precise feeding times may further support the results of these analyses. Anyway, the results of this study may contribute to a better understanding of the effect of phloem feeding on plant biochemistry. Although secondary metabolites are not directly implicated in vital cell functions such as respiration and division, they are a subject of considerable interest, particularly because of their utility in human medicine and nutrition. They have been widely studied by plant biochemists who attribute to them physiological, agronomic and ecological importance (Bennett \& Wallsgrove, 1994; Pichersky et al., 2000; Bourgaud et al., 2001; Wink, 2003). The wide diversity of chemical structures is related to a multiplicity of functions. Among the different secondary metabolites, the phenolic compounds stand out because of their capability to defend plants from herbivores (Schowalter, 2006). The literature reports that the phenolics have deterrence properties and toxicity against different species of insects (Miles et al., 1999; Appel, 
1993; Golawska et al., 2009). Our analysis of the yarrow system started with phloem feeding aphids rather than leaf feeding chrysomelids which are also present in yarrow fields (Morlacchi, 2010). M. persicae can easily be reared on yarrow and proved to be an ideal model of a phloem feeder for studying plant-aphid interactions (Morlacchi, 2010). Presumably, the here described processing procedure could be applied to study the response of the plant to chrysomelid feeding.

The literature provides guidance on the selection of instruments, the chemometric methods and the interpretation of the results (Jiao et al., 2010; Rodriguez-Nogales, 2010). In this paper, we carried out preprocessing to obtain the optimal separation of the analytes, even when present in small amounts. The methanol extract of A. collina is a complex pool of molecules and the corresponding chromatographic profiles showed a sequence of overlapping peaks. Thus, the preprocessing required great effort to find the best chromatographic conditions that separate phenolic compounds. Finally, the preprocessing procedure resulted in a satisfactory methodology fulfilling the criteria of optimal separation of analytes, good chromatographic peak shape and robustness of the results. This allowed us to directly proceed to the processing phase and carry out chemometric analyses with a standardized methodology. This step is considered important for an efficient identification of peaks separating infested from non-infested plants. It does not compromise the possibility for further refining preprocessing procedures (Hendriks et $a l, 2005)$ and re-analyses of the here obtained results.

Chemometric analyses are widely used to extract information from chemical system (Bereton, 2003; Jiao et al., 2010; Rodriguez-Nogales et al., 2010). A stepwise multivariate analysis is a powerful technique for identifying the difference between treatments with respect to several variables and for classifying the discriminatory compounds. Hydroxycinnamic acids previously found in A. collina have no significant discriminatory effects. This result is in contrast to the one obtained by other authors (Miles et al., 1999; Cipollini et al., 2008), which have found that chlorogenic acid and other caffeic acid derivatives increased during feeding of other insects species. The contrast is probably due to the different mechanisms that plants activate in relation to the herbivore feeding behavior (Hao et al., 2008). Hopkins et al., (2009) explained the role of glucosinolates as defensive compounds and reported a huge variation in the biological activity of individual compounds suggesting that the total secondary metabolites concentration is not able to explain exhaustively their biological effects. Moreover, the authors reported the qualitative and quantitative variation respect to the plant tissues and ontogenetic stages and the extreme variation in the role that such secondary metabolites play for different insects and herbivores.

The most important finding is that aphid feeding changes the chemical composition of the host plants. Specifically, we obtained two peaks (6 and 29 in the chromatogram) able to separate infested from non-infested plants. The coefficient value of the peak 6 was higher respect to those of the 29 , suggesting a major discriminatory capacity of this compound. Since the extraction procedure and the HPLC method were specific to phenolic compounds, we suppose that the molecules corresponding to 6 and 29 peak belong to this specific chemical class. Phenolic compounds are distributed in different 
tissues and subcellular leaf structures. It is of particular interest to evaluate a possible use in pest management systems aiming at phloem feeding insects (Beninger et al., 2004; Ranger et al., 2007). The work shows that the plant responds with the production of two unknown phenolics to aphid infestation. Nevertheless, the exact nature of the chemicals is currently unknown, and work is under way to identify the substances responsible for producing these peaks. To further improve the insight into the response of the plant to phloem feeding, efforts should be made to localize the production within the plant. Morevover, the work deals exclusively with the response of the plant to aphid infestation. The effect of phenolics and other substances on aphid development will be treated in a subsequent paper.

\section{ACKNOWLEDGEMENTS}

We appreciate the assistance of Prof. M. Acutis (Dipartimento di Produzione Vegetale, Facoltà di Agraria, Università degli Studi di Milano, Milano) in statistical analyses.

\section{REFERENCES}

APPEL H.M., 1993 - Phenolics in ecological interactions: The importance of oxidation. J. Chem. Ecol., 19 (7): 1521-1552.

BARBARANELLI C., 2006 - Le analisi multivariate - Le analisi dei dati con SPSS. Vol. 2. Chapter 4. Edizioni Universitarie di Lettere Economia e Diritto, Milano, 171-206.

Benderoth M., Textor S., Windor A.J., Mitchell-Olds T., Gershenzon J., Kroymann J., 2006 - Positive selection driving diversification in plant secondary metabolism. Proc. Natl. Acad. Sci. USA., 103 (24): 9118-9123.

Benedek B., GJoncaj N., SAuKel J., Kopp B., 2007 - Distribution of phenolic compounds in Middleeuropean Taxa of the Achillea millefolium L. aggregate. Chem. Biodivers., 4 (5): 849-857.

Beninger C.W., Abou-Zaid M.M., Kister A.L.E., Hallett R.H., Iqbal M.J., Grodzinski B., HALL J.C., 2004 - A flavanone and two phenolic acids from Chrysanthemum morifolium with phytotoxic and insect growth regulating activity. J. Chem. Ecol., 30 (3): 589-606.

BENNETT R.N., WALLSGROVE R.M., 1994 - Secondary metabolites in plant defence mechanisms. New Phytol., 127 (72): 617-633.

Bourgaud F., Gravot A., Milesi S., GonTIER E., 2001 - Production of plant secondary metabolites: a historical perspective. Plant Sci., 161 (5): 839-851.

BRERETON R.G., 2003 - Chemometrics. Data analysis for the laboratory and chemical plant. Wiley, Chichester, West Sussex, England, 1-11.

Cipollini D., Stevenson R., Enright S., Eyles A., Bonello P., 2008 - Phenolic metabolites in leaves of the invasive shrub, Lonicera maackii, and their potential phytotoxic and antiherbivore effects. J. Chem. Ecol., 34 (2): 144-152.

De Backer B., Debrus B., Lebrun P., Theunis L., Dubois N., Decock L., Verstraete A., Hubert P., ChARLIER C., 2009 - Innovative development and validation of an HPLC/DAD method for the qualitative and quantitative determination of major cannabinoids in cannabis plant material. J. Chromatogr. B., 877 (32): 4115-4124.

Dicke M., Van Poecke R.M.P., De Boer J.G., 2003 - Inducible indirect defence of plants: from mechanisms to ecological functions. Basic. Appl. Ecol., 4 (1): 27-32. 
Dixon A.R., PaIVA N.L., 1995 - Stress-induced phenylpropanoid metabolism. The Plant Cell., 7 (7): 1085-1097.

DiXON A.R., 2001 - Natural products and plant disease resistance. Nature, 411 (6839): 843-847.

Edreva A., Velikova V., Tsonev T., Dagnon S., Gürel A., Aktaş L., Gesheva E., 2008 - Stressprotective role of secondary metabolites: diversity of functions and mechanisms. Gen. Appl. Plant Physiology, 34 (1-2): 67-78.

EHRLICH P.R., RAVEN P.H., 1964 - Butterflies and plants: a study in coevolution. Evolution, 18: 586-608.

FRAENKEL G.S., 1959 - The raison d'etre of secondary plant substances. These odd chemicals arose as a means of protecting plants from insects and now guide insects to food. Science, 129: $1466-1470$.

FutuYma D.J., Agrawal A.A., 2009 - Macroevolution and the biological diversity of plants and herbivores. Proc. Natl. Acad. Sci. USA, 106 (43): 18054-18061.

Garey K.W., Lai D., DaO-Tran T.K., Gentry L.O., Hwang L.Y., Davis B.R., 2008 - Interrupted time series analysis of vancomycin compared to cefuroxime for surgical prophylaxis in patients undergoing cardiac surgery. Antimicrob. Agents Ch., 52 (2): 446-451.

Giorgi A., Mingozzi M., MAdeo M., Speranza G., Cocucci M., 2009 - Effect of nitrogen starvation on the phenolic metabolism and antioxidant properties of yarrow (Achillea collina Becker ex Rchb.). Food Chem., 114 (1): 204-211.

GOLAWSKA S., LUKASIK I., 2009 - Acceptance of low-saponin lines of alfalfa with varied phenolic concentrations by pea aphid (Homoptera: Aphididae). Biologia, 64 (2): 377-382.

GracE S.G., LOGAN B.A., 2000 - Energy dissipation and radical scavenging by the plant phenylpropanoid pathway. Phil. Trans. R. Soc. Lond. B, 355 (1402): 1499-1510.

HADACEK F., 2002 - Secondary metabolites as plant traits: current assessment and future perspectives. Crit. Rev. Plant Sci., 21 (4): 273-322.

Halbert S.E., Corsini D., WiebE M., VAUGHN S.F., 2008 - Plant-derived compounds and extracts with potential as aphid repellents. Ann. Appl. Biol., 154 (2): 303-307.

HARTMANN T., 2004 - Plant-derived secondary metabolites as defensive chemicals in herbivorous insects: a case study in chemical ecology. Planta, 219 (1): 1-4.

Hao P., Liu C., Wang Y., Chen R., Tang M., Du B., Zhu L., He G., 2008 - Herbivore-induced callose deposition on the sieve plates of rice: an important mechanism for host resistance. Plant physiol., 146: 1810-1820.

Hendriks M.M.W.B., Cruz-Juarez L., De Bont D., Hall R.D., 2005 - Preprocessing and exploratory analysis of chromatographic profiles of plant extracts. Anal. Chim. Acta, 545 (1): 53-64.

HiLl D.S., 1983 - Agricultural insect pests of the tropics and their control. 2nd ed. Cambridge University Press, New York, 528 pp.

HOPKINS R.J., VAN DAM N.M., VAN LOON J.J.A., 2009 - Role of glucosinolates in insect-plant relationships and multitrophic interactions. Annu. Rev. Entomol., 54: 57-83.

ICH, In: International Conference on harmonization of technical requirements for registration of pharmaceuticals for human use, validation of analytical procedures: text and methodology Q2 (R1), 2005.

JiAo Z., Si X-X., Li G-K., Zhang Z-M., XU X-P., 2010 - Unintended compositional changes in transgenic rice seeds (Oryza sativa L.) studied by spectral and chromatographic analysis coupled with chemometrics methods. J. Agric. Food Chem., 58 (3): 1746-1754.

Kuśnierczyk A., Winge P., Jørstad T.S., Troczyńska J., Rossiter J.T., Bones A.M., 2008 Towards global understanding of plant defence against aphids - timing and dynamics of early Arabidopsis defence responses to cabbage aphid (Brevicoryne brassicae) attack. Plant Cell Environ., 31 (8): 1097-1115. 
MiLes P.W., 1999 - Aphid saliva. Biol. Rev., 74 (1): 41-85.

Moran P.J., Cheng Y., Cassel J.L., Thompson G.A., 2002 - Gene expression profiling of Arabidospis thaliana in compatible plant-aphid interactions. Arch. Insect Biochem., 51 (4): 182-203.

MORLACCHI P., 2010 - Interazioni multi trofiche tra popolazioni in sistemi di colture officinali: Coccinella septempunctata Linneus e Macrosiphoniella millefolii De Geer su Achillea collina Becker. Ph.D. dissertation. Università degli Studi di Milano.

RAMACHANDRA RAO S., RAVISHANKAR G.A., 2002 - Plant cell cultures: chemical factories of secondary metabolites. Biotechnol. Adv., 20 (2): 101-153.

Ranger C.M., Singh A.P., Johnson-Cicalese J., Polavarapu S., Vorsa N., 2007 - Intraspecific variation in aphid resistance and constitutive phenolics exhibited by the wild blueberry Vaccinium darrowi. J. Chem. Ecol., 33 (4): 711-729.

Rodriguez-Nogales J.M., Cifuentes A., GarCia M.C., Marina M.L., 2010 - Improved methodology for the characterisation of transgenic Bt-11 maize cultivars using RP-HPLC profiles of albumin, globulin, prolamin, and glutelin protein fractions and chemometric analysis. Food Chem., 120 (4): 1229-1237.

Schowalter T.D., 2006 - Insect Ecology. An Ecosystem Approach. London Academic Press, London, $572 \mathrm{pp}$.

VAn EMden H.F., EAstop V.F., Hughes R.D., WAY M. J., 1969 - The Ecology of Myzus persicae. Annu. Rev. Entomol., 14: 197-270.

WALLING L.L., 2000 - The myriad plant responses to herbivores. J. Plant Growth Regul., 19 (2): 195-216.

WINK M., 2003 - Evolution of secondary metabolites from an ecological and molecular phylogenetic perspective. Phytochemistry, 64 (1): 3-19.

Wittstock U., Agerbirk N., Stauber E.J., Olsen C.E., Hippler M., Mitchell-Olds T., GershENZON J.,Vogel H., 2004 - Successful herbivore attack due to metabolic diversion of a plant chemical defense. Proc. Natl. Acad. Sci. USA, 101 (14): 4859-4864.

Zhao W., Morgan J.T., Davis C.E., 2008 - Gas chromatography data classification based on complex coefficients of an cutoregressive model. Journal of Sensors, 2008: 1-8.

AnNAmaria Giorgi - Dipartimento di Produzione Vegetale (Di.Pro.Ve.), Università degli Studi di Milano, Via G. Celoria 2, I - 20133, Milano.E-mail: anna.giorgi@unimi.it

Moira Madeo, Johann Baumgärtner, Giuseppe Carlo Lozzia - Dipartimento di Protezione dei Sistemi Agroalimentare e Urbano e Valorizzazione delle Biodiversità (Di.P.S.A.), Università degli Studi di Milano, Via G. Celoria 2, I - 20133, Milano. E-mail: moira.madeo@unimi.it; johann.baumgartner@unimi.it; giuseppe.lozzia@unimi.it

Accepted 30 August 2010 